\title{
Anthelmintic resistance. An overview of the situation in the Nordic countries
}

\author{
Carl Fredrik Ihler \\ From Parasite infections of domestic animals in the Nordic countries - emerging threats and challenges. \\ The 22nd Symposium of the Nordic Committee for Veterinary Scientific Cooperation (NKVet) \\ Helsinki, Finland. 7-9 September 2008
}

\section{Introduction}

Gastrointestinal nematodes in grazing animals cause major production losses and represent an animal welfare problem worldwide. For decades use of anthelmintics has been central in the control programs of these parasites. This intensive use of anthelmintic drugs has resulted in problems with resistance to the anthelmintic drugs available today. Resistance to all classes of broadspectrum anthelmintics available benzimidazoles (BZ), imidothiazoles-tetrahydropyrines and macrocyclic lactones has been reported [1].The time from introducing a new class of anthelmintic drugs until resistance has been detected seems to be less than 10 years [1]. As time has passed problems of multiresistance to more than one class has occurred as well. Multiresistant Haemonchus contortus has become a major threat to the whole small ruminant industry in part of South Africa and in the South-East of USA [2,3].

At present, resistant nematode populations are detected in all our naturally grazing species; sheep, goats, cattle and horses [1] . In pigs, resistance to pyrantel, levamisole and benzimidazoles in Oesophagostumum spp have been detected $[4,5]$.

\section{Development of anthelmintic resistance}

Anthelmintic resistance (AR) is defined by Køhler as genetically transmitted loss of sensitivity of a drug in worm populations that were previously sensitive to the same drug [6]. In a worm population, alleles coding for resistance will be present as a result of mutations, also in unexposed populations. Resistance will develop if there are survival advantages for parasites carrying these

Correspondence: carl.ihler@veths.no

Department of Companion Animal Clinical Sciences, Norwegian School of Veterinary Science, P:O 8146, 0030 Dep Oslo, Norway alleles [7]. Treating worms with drugs corresponding to the "resistance" alleles will give these worms an advantage and the frequency of resistant worms in the population will increase. The frequency of alleles coding for resistance at the time of exposure to a drug will be important for the rate of the development of a resistant population.

The amount of anthelmintic drugs used and thereby the exposure will influence the development of AR. Therefore, it is important to establish de-worming strategies that take this into consideration. Parasite control programs must have a specific aim and the use of drugs must be kept to a minimum to achieve this aim. For horses a reasonable aim of a parasite control program would be to eliminate the large strongyles and have the cyathostomes and Parascaris equorum infestations under control.

The prepatent period of a parasite will be of importance. Species with short prepatent periods will have more generations during a grazing season. Frequent anthelmintic treatment will then expose more generations of these parasites than species with longer generation intervals. The trichostrongyles in ruminants (prepatent period approx. 3 weeks) and cyathostomes in horses (prepatent period 6-8 weeks) are examples of short generation interval species. Strongylus vulgaris has, however, a prepatent period of 6 months. This difference in generation interval might be the reason why resistance is common in cyathostomes and has not been reported in S. vulgaris so far.

Parasites in refugia represent the fraction of the worm population not exposed to the drug when animals are treated. The free living stages of the parasites are the most important part of the refugia. The higher the proportion of parasites in refugia the slower the development of resistance as the selection pressure of the whole 
population is lower $[8,9]$. The importance of refugia can be illustrated by looking at the difference in development of resistance in Australia compared to New Zealand. In New Zealand, where the climate is wet, up to $75 \%$ of the $H$. contortus population are larval stages on the pasture [10], which is considerably higher than in the more dry climate in Australia. In spite of the fact that the benzimidazoles and levamisole have been used over the same period of time, the resistance to these drugs was detected much later in New Zealand [11].

In the Nordic countries parasites which do not overwinter on the pasture, such as $H$. contortus, have only a small proportion in refugia and hence have a greater selection pressure when animals are treated in this period than in species where larval stages overwinter on pasture.

Selective treatment of animals will also have impact on the refugia. In horses selective treatment of animals expelling $>200$ eggs per gram when treated in the grazing season has been suggested. This will reduce the exposed proportion of the population and thus dilute the resistant alleles in the population. Such strategy will, however, need an egg count of faeces from every single animal before treatment. This strategy is widely used in Denmark [12].

\section{Detection of anthelmintic resistance}

Different methods, both in vivo and in vitro methods, have been used to detect and monitor AR. Faecal egg count reduction test is the most used in vivo method and gives an estimation of the efficacy of the drug by comparing the egg counts pre and post treatment. Guidelines for the method are described by Coles et al. [13]. The accuracy of the method depends on a correlation between egg counts and worm burdens which is not always present. Nematodes like Trichostrongylus colubriformis and Ostertagia circumcincta show little correlation whereas $H$. contortus show good correlation $[14,15]$.

The controlled test is the most reliable method but is rarely used because of high costs. This test uses untreated control groups and the parasitized animals are euthanized about 10 days post treatment and a necropsy is subsequently preformed.

Different in vitro methods are described. The egg hatch assay (EHA) was first described by Le Jambre for the detection of BZ- resistance [16]. Modification of the original method is developed by Taylor et al. [17] and the method is mostly used for the detection of possible BZ resistance in sheep and horses [18].The larval development assay (LDA) uses the ability of the anthelmintic to arrest the normal development from eggs to L3 larvae. By observing the proportion of L3 larvae developed in different concentrations of an anthelmintic, a LC50 value can be determined. In this assay anthelmintics with different modes of action can be tested at the same time and it has been useful in surveys of sheep nematodes [19]. The test has shown to be difficult to use in equine strongyles due to repeatability problems [20].

A biochemical test for detection of $\mathrm{BZ}$ resistance based on reduced affinity to tubulin has also been introduced [21]. The method requires a large number of larvae and is therefore unsuitable for field surveys [17].

Molecular based tests are only in use for detection of $\mathrm{BZ}$ resistance as the molecular mechanisms for resistance to tetrahydropyrimidenes and macrocyclic lactones are not fully understood [18]. The principle of the diagnosis of resistance relies on a multiple allele specific PCR. The method has been used for testing ovine trichostrongyles and equine small strongyles for BZ resistance. The most common mechanism for BZ resistance in ovine trichostrongyles involves a phenylalanine to tyrosine mutation located at residue 200 of the isotype 1 beta-tubulin gene [22]. The same polymorphism is described in equine small strongyles [23].

\section{Anthelmintic resistance in gastrointestinal nematodes in the Nordic countries}

AR most likely represents a problem of all Nordic countries although few studies have been performed in Finland and Iceland (Oksanen and Sigurdsson, personal communication).

The Danish veterinary parasitologists have been important expanding our knowledge of AR in the Nordic countries. In the early 90s the Centre for Experimental Parasitology in Copenhagen, lead by the enthusiastic Professor Peter Nansen, performed many studies and research programs in this field involving $\mathrm{PhD}$ students from many countries. The Centre through Dr. Henrik Bjørn, also inspired research on anthelmintic resistance in Sweden and Norway together with Dr. Peter Waller.

In Denmark, several studies have been performed on AR in small ruminants, horses and swine. The first study on resistance in sheep nematodes in Denmark was published in the early 90 s where resistance to levamisole in Ostertagia circumcincta was described [24]. Later Maingi et al. [25] reported evidence of BZ, ivermectin and levamisole resistance in caprine trichostrongyles in a survey from 15 Danish goat herds. Most other studies concerning AR in sheep nematodes in Denmark have focused on comparison of different in vitro tests with the faecal egg count reduction test and to my knowledge no surveys have been performed to evaluate changes in the resistance situation over the last 10-15 years.

In Sweden there are no published surveys on resistance in small ruminant nematodes while there is one single report on the situation in Norway [26]. In this 
report BZ-resistance was detected in four out of 26 herds. Resistance in O. circumcincta was found in all 4 herds while resistance in Nematodirus battus and $H$. contortus were suspected in one of these herds.

In swine, Roepstorff et al. [4] confirmed resistance to pyrantel citrate in Oesophagostomum spp. in Denmark. Later Bjørn et al. [27] confirmed side-resistance between levamisole and pyrantel in the same species. To my knowledge no studies on AR in swine parasites have been conducted in the other Nordic countries. The prevalence of resistant Oesophagostomum spp. is reported from Germany is estimated to $2-3.5 \%$ [5].

No studies concerning resistance in cattle nematodes have so far been published from the Nordic countries. Worldwide there are however studies confirming resistance to all three major classes of anthelmintic drugs in cattle nematodes [1]. Looking at the experience of other countries, anthelmintic resistance in cattle nematodes might be a threat to the cattle industry in our countries as well.

Anthelmintic resistance in intestinal parasites of the horse is without doubt the area where most studies concerning AR are conducted in the Nordic countries. In Sweden Nilsson et al. [28] reported BZ-resistance in equine small strongyles. Later Bjørn et al. [29] and Ihler [30] published high prevalence of BZ-resistance in Denmark and Norway.

Pyrantel resistance in small strongyles has also been reported from the Nordic countries [30-32]. Resistance to macrocyclic lactones in the equine small strongyles has so far not reported, but there is a worldwide agreement that it is just a question of time before this will occur.

However, reports on resistance to ivermectin in the equine roundworm $P$. equorum have been published. From Denmark Schougaard and Nielsen [33] have reported reduced efficacy of ivermectin as have Lindgren et al. from Sweden [34]. Resistance to ivermectin in the equine roundworm is suspected in Norway, but a proper study on this has not been conducted yet.

Although most reports on AR in nematodes concern anthelmintics to ruminant and horse parasites, there are also reports of resistance in the canine hookworm Ancylostoma caninum to pyrantel $[35,36]$. No reports in the Nordic countries on resistance to canine nematodes have been published.

\section{Reducing the development of AR}

$A R$ is a major problem when controlling parasite infections in production animals and horses worldwide. As documented, the reason for development of resistance to anthelmintics is a selection of resistant individuals in the worm population as a result of anthelmintic exposure. Therefore, efforts to reduce this exposure will slow down further development of resistance but will not reverse the existing resistance in a population. The most obvious way to reduce the exposure is to reduce the use of anthelmintic drugs and look to other ways to control parasites beside anthelmintic use.

As no new broad-spectrum anthelmintic drugs with new modes of action have been introduced since the macrocyclic lactones in the $80 \mathrm{~s}$, it is necessary to take the warnings of $A R$ as a major problem seriously.

Improvement of the grazing management is important in reducing the use of anthelmintics. Reduction of the stocking rate, reducing the grazing season on the pastures and mixed grazing between animal species are all key factors. Furthermore, the animals have to be treated at times when the effect of treatment is best and underdosing is to be avoided.

Biological control of nematodes is an interesting way of reducing the use of anthelmintic drugs. The principle of biological control is the use of the natural enemies of the nematodes to reduce the infection level on pastures [37]. These methods have no intention of eliminating the free living larval stages but aim to reduce them to a level where no clinical or subclinical effects are present while stimulating an acquired immune response. Nematode destroying fungi have been a potential candidate in biological control and the fungus Duddingtonia flagrans has shown to be effective through several studies [38-41]. Most studies on the effect of feeding D. flagrans have been based on daily intake of the fungi through feed supplementation. Mineral blocks containing fungal spores or slow-release devices might be practical ways of feeding the fungal material in the future and make the method practical in commercial farming.

Development of effective vaccines against intestinal parasites will allow the opportunity to reduce the use of antiparasitic drugs. In spite of great efforts making vaccines protecting grazing animals against helminth infections, only a vaccine against the bovine lungworm Dictyocaulus viviparus is commercially available [42]

\section{How to deal with the challenge of AR in the Nordic countries}

Keeping in mind that new classes of anthelmintic drugs with different mode of action have not been introduced since the $80 \mathrm{~s}$ and that the AR problem seems to escalate worldwide, we have to take action. Monitoring the resistance situation by systematic surveys in different worm populations is an important means to control AR. I think that the agricultural industry has to be financially responsible for this work through their organisations. We have good knowledge on the development of AR and we know how to deal with it, but we lack information on the development AR over time in our region. 
Prescription from veterinarians must be the only way for the farmers to obtain anthelmintics. This will subsequently demand a qualified advice from the veterinarians in order to give the best advice concerning type of formulations and when to treat the animals to achieve the best effect of the treatment and at the same time take development of AR into consideration. This is a challenge in the education of both veterinary students and veterinary colleagues.

\section{Published: 13 October 2010}

\section{References}

1. Kaplan RM: Drug resistance in nematodes of veterinary importance. A status report. Trends Parasitol 2004, 20:477-481.

2. Van Wyk JA, Stenson MO, Van der Merwe JS, Vorster RJ, Viljoen PG: Anthelmintic resistance in South-Africa: surveys indicate indicate an extremely serious situation in sheep and goat farming. Onderspoort J Vet Res 1999, 66:273-284.

3. Mortensen LL, Williamson LH, Terrill TH, Kircher RA, Larsen M, Kaplan RM: Evaluation of prevalence and clinical implications of anthelmintic resistance in gastrointestinal nematodes of goats. J Am Vet Med Assoc 2003, 223:495-500.

4. Roepstorff A, Bjørn H, Nansen P: Resistance of Oesophagostomum spp. in pigs to pyrantel citrate. Vet Parasitol 1987, 24:229-239.

5. Gerwert S, Failing K, Bauer C: Prevalence of levamisole and benzimidazole resistance in oesophagostomum populations of pig breeding farms in North Rhine-Westphalia, Germany. Parasitol Res 2002, 88:63-68.

6. Køhler P: The biochemical basis of anthelmintic action and resistance. Int J Parasitol 2001, 31:336-345

7. Gilleard JS, Beech N: Population genetics of anthelmintic resistance in parasitic nematodes. Parasitology 2007, 134:1133-1147.

8. Martin PJ, Le Jambre LF, Claxton JH: The impact of refugia on the development of thiabendazole resistance in Haemonchus contortus. Int J Parasitol 1981, 11:35-41.

9. van Wyk JA: Refugia- overlooked as perhaps the most potent factor concerning the development of anthelmintic resistance. Onderspoort J Vet Res 2001, 66:55-67.

10. Le Jambre LF: Anthelmintic resistance in gastro intestinal nematodes of sheep. The epidemiology and control of gastro intestinal parasites of sheep CSRIO, Division of Animal Health, MelbourneDonald AD, Southcott WH, Dineen JK 1979, 109

11. Kettle PR, Vlassoff A, Lukies JM, Ayling JM, McMurtry LW: A survey of nematode control measures used by sheep farmers and of anthelmintic resistance on their farms. Part I. North Island and the Nelson region of the South Island. NZ Vet J 1981, 29:81-83.

12. Nielsen MK, Monrad J, Olsen SN: Prescription-only anthelmintics- a questionnaire survey of strategies for surveillance and control of equine strongyles in Denmark. Vet Parasitol 2006, 135:47-55.

13. Coles GC, Bauer C, Borgsteede FH, Geerts S, Klei TR, Taylor MA, Waller PJ: World Association of Advancement of Veterinary Parasitology (WAAVP) methods for detection of anthelmintic resistance in nematodes of veterinary importance. Vet Parasitol 1992, 44:35-44.

14. Sangster NC, Whitlock HV, Russ IG, Gunawan M, Griffin DL, Kelly JD: Trichostrongylus colubriformis and Ostertagia circumcincta resistant to levamisol, morantal tartrate and thiabendazole: occurrence of field strains. Res Vet Sci 1979, 27:106-110.

15. Martin PJ, Anderson N, Jarrett RG: Resistance to benzimidazole resistance in field strains of Ostertagia and Nematodirus in sheep. Aust Vet J 1985 62:38-43.

16. Le Jambre LF: Egg hatch as an vitro assay of thiabendazole resistance in nematodes. Vet Parasitol 1976, 2:385-391.

17. Taylor MA, Hunt KR, Goodyear KL: Anthelmintic resistance detection methods. Vet Parasitol 2002, 28:183-194.

18. Coles GC, Jackson F, Pomroy WE, Prichard RK, von SamsonHimmelstjerna G, Silvestre A, Taylor MA, Vercruysse J: The detection of anthelmintic resistance in nematodes of veterinary importance. Vet Parasitol. 2006, 136:167-85.

19. Lacey E, Redwin JM, Gill JH, Demargherity VM, Waller PJ: A larval development assay for the simultaneous detection of broad spectrum anthelmintic resistance. Resistance of parasites to antiparasitic drugs.MSD AGVET, Rahway, NJ.Boray JC 1990, 177-184.

20. Tandon R, Kaplan RM: Evaluation of a larval development assay (DrenchRite ${ }^{\circledR}$ ) for the detection of anthelmintic resistance in cyathostomin nematodes of horses. Vet Parasitol 2004, 121:125-142.

21. Sangster NC, Prichard RK, Lacey E: Tubulin and benzimidazole resistance in Trichostrongylus colubriformis (nematoda). J Parasitol 1985, 71:645-651.

22. Elard L, Cabaret J, Humbert JF: PCR diagnosis of benzimidazolesusceptibility or-resistance in natural population of the small ruminant parasite, Teladorsagia circumcincta. Vet Parasitol 1999, 80:231-237.

23. Pape M, Posedi J, Failing K, Schnieder T, von Samson-Himmelstjerna G: Analysis of the beta-tubulin codon 200 genotype distribution in benzimidazole-susceptibility and -resistance cyathostome population. Parasitology 2003, 127:53-59.

24. Bjørn H, Monrad J, Nansen P: Anthelmintic resistance in nematode parasites of sheep in Denmark with special emphasis on levamisole resistance in Ostertagia circumcincta. Acta vet Scand 1991, 32:145-154.

25. Maingi N, Bjørn H, Thamsborg SM, Bøgh HO, Nansen P: A survey of anthelmintic resistance in nematode parasites of goats in Denmark. Vet Parasitol 1996, 66:53-56.

26. Reiersen A, Ihler CF: Ormemiddelresistens hjå saueparasittar i Norge. Proceedings Husdyrforsøksmøtet 1996, 401-405.

27. Bjørn H, Roepstorff A, Waller PJ, Nansen P: Resistance to levamisole and cross-resistance between pyrantel and levamisole in Oesaphagostomum qudrispinulatum and Oesophagostomum dentatum of pigs. Vet Parasitol 1990, 37:21-30

28. Nilsson O, Lindholm A, Christensson D: A field evaluation of anthelmintics in horses in Sweden. Vet Parasitol 1989, 32:163-171.

29. HBj rn, Sommer C, Schoug冈rd H, Henriksen SA, Nansen P: Resistance to benzimidazole anthelmintics in small strongyles (Cyathostominae) of horses in Denmark. Acta vet Scand 1991, 32:253-260.

30. Ihler CF: A field survey on anthelmintic resistance in equine small strongyles in Norway. Acta vet Scand 1995, 36:135-143.

31. Craven J, Bjørn H, Henriksen SA, Nansen P, Larsen M, Lendal S: Survey of anthelmintic resistance on Danish horse farms, using 5 different methods of calculating faecal egg count reduction. Equine vet $J 1998$, 30:289-293.

32. Lind EO, Kuzmina T, Uggla A, Waller PJ, Höglund J: A field study on the effect of some anthelmintics on cyathostomins of horses in Sweden. Vet Res Commun 2007, 31:53-65.

33. Schougaard $\mathrm{H}$, Nielsen MK: Apparent ivermectin resistance of Parascaris equorum in foals in Denmark. Vet Rec 2007, 160:439-440.

34. Lindgren $\mathrm{K}$, Ljungvall $\mathrm{O}$, Nilsson $\mathrm{O}$, Ljungström $\mathrm{BL}$, Lindahl $\mathrm{C}$, Höglund J: Parascaris equorum in foals and in their environment on a Swedish stud farm, with notes on treatment failure of ivermectin. Vet Parasitol 2008, 151:337-343.

35. Jackson $R$, Lance $D$, Townsend $K$, Stewart $K$ : Isolation of antehelmintic resistant Ancylostoma caninum. N Z Vet J 1987, 35:215-216.

36. Kopp SR, Kotze AC, McCarthy JS, Coleman GT: High-level pyrantel resistance in the hookworm Ancylostoma caninum. Vet Parasitol 2007, 143:299-304

37. Larsen M: Biological control of nematodes in sheep. J Anim Sci 2006, 84 E133.

38. Faedo M, Barnes EH, Dobson RJ, Waller PJ: The potential of nematophagous fungi to control the free-living stages of of nematode parasites of sheep.: Pasture plot study of Duddingtonia flagrans. Vet Parasitol 1998, 76:129-135.

39. Larsen M, Faedo M, Waller PJ, Hennessy DR: The potential of nematophagous fungi to control the free-living stages of of nematode parasites of sheep: Studies with Duddingtonia flagrans. Vet Parasitol 1998, 76:121-128.

40. Fontenot ME, Miller JE, Peña MT, Larsen M, Gillespie A: Efficiency of feeding Duddingtonia flagrans chlamydospores to grazing ewes on reducing availability of parasitic nematode larvae on pasture. Vet Parasitol 2003, 118:203-213.

41. Waller PJ, Schwan O, Ljungström BL, Rydzik A, Yeates GW: Evaluation of biological control of sheep parasites using Duddingtonia flagrans under 
commercial farming conditions on the island of Gotland, Sweden. Vet Parasitol 2004, 126:299-315.

42. Smith WD, Zarlenga DS: Developments and hurdles in generating vaccines for controlling helminth parasites of grazing ruminants. Vet Parasitol 2006, 139:347-459.

doi:10.1186/1751-0147-52-S1-S24

Cite this article as: Ihler: Anthelmintic resistance. An overview of the situation in the Nordic countries. Acta Veterinaria Scandinavica 201052 (Suppl 1):S24

Submit your next manuscript to BioMed Central and take full advantage of:

- Convenient online submission

- Thorough peer review

- No space constraints or color figure charges

- Immediate publication on acceptance

- Inclusion in PubMed, CAS, Scopus and Google Scholar

- Research which is freely available for redistribution 